\title{
Collaboration Model in E-Learning for Universities Based on Agents
}

\author{
Augusto E. Bernuy ${ }^{1}$ and Víctor M. García ${ }^{2}$ \\ 1 Facultad de Sistemas, Universidad Nacional de Ingeniería, Lima-Perú. \\ Facultad de Ingeniería, Universidad Pontificia de Salamanca \\ Madrid, España,28040 Madrid, abernuy@uni.edu.pe \\ 2 Facultad de Ingeniería, Universidad Pontificia de Salamanca, \\ Madrid, España, 28040 Madrid, victor.martin@upsam.net
}

\begin{abstract}
The paper presents the basic requirements that must cover distance education processes ("e-learning") in universities. We show the concepts of instruction design, an adaptive learning model for evaluating necessities, accreditation, and quality proposal. The experience indicates that to obtain good results we should evaluate the differences between the criteria of the professor and the criteria of the student about: the educative aspects, the user reaction (in each perspective), the reading aspects (in the student) and complementary material. Thus, collaboration and quality are managed when the learning process is based on design, the designer, the professor, participation level, student profile and his characteristics, the motivations and evaluations. We will need continuous reflection and evaluation for the organizations and the structured learning programs, having looked for educative yield and productive development. The paper is our contribution to work with ethical issues and human collaboration for the information society
\end{abstract}

\section{Introduction}

"Depend on the binomial education/communication conception; it will be the use of tools in education and teaching. There are two ways to understand them and to assume this couple: the directional and vertical, and another one that considers the pupil such as a subject of a process in which student is learning with others. Firstly, 
the use of means will reproduce the one direction and the impossibility of logic relation. Secondly, that use will be made in a space whose protagonists are true interlocutors." [5] The university plays a decisive role in the development of citizens and modern societies, as measured by the levels of social, cultural and economic development, active citizenship and ethical values. In addition universities must have policies that guarantee commonality in both contents and programs in order to obtain permanent learning as a basis for the continuation of learning all through life. The alternative of remote classes (virtual formation or e-learning), efficient tools and the improvement of the quality appear like fluid experiences through the web, but we are looking them in permanent ways. We define e-learning, electronic learning, as technological solutions that integrate software and hardware to promote the acquisition and operation of knowledge, abilities, skills, capacities and collaboration between the users. This is an approach to a new way of collaboration for distance necessities in order to evaluate the contents and the design of learning programs.

\section{Instruction design}

In 1985, Gagne [4] distinguished two types of conditions, internal and external. The internal ones include attention, motivation and memory. The external ones are factors that surround their behavior, including the environment and the time of the events that affect the stimulus. The instruction design includes a sequence of nine educational events and their processes of learning [4].

The instruction design must include: (1) Analyze requirements, (2) Select means, and (3) Design the educational events. The educational technologist must have present the following concepts to develop instruction methods: (1) the abilities at the beginning and each new learned ability that will be constructed based on previous abilities, (2) the analysis phase must identify and describe abilities and knowledge for an educational objective, (3) the objectives of the last level are dominated before a higher level, (4) the objectives must be written in concrete terms of the behavior, and (5) positive reinforcement is repeated. The recommended steps are given in [4].

In the traditional model of the university we work to protect ideas, investigations and experimentations that lead to us to create knowledge. Remote education allows new value added for the society: (1) some people cannot mobilize themselves for work, (2) some people are marginalized by physical and corporal problems, (3) those that look for education in other countries, and (4) those that cannot pay the cost of actual education.

\section{Model of programs "e-learning"}

The Mind-Mapping for Web Instruction and Learning [3] is based on three components: (1) Object of learning, (2) Strategies of learning, and (3) Design of outlooks for learning. They help in the processes of learning such as personal abilities, declaratory knowledge, and problem solution, among others. For each 
learning process we identify an appropriate strategy and construct the groups that represent associated events.

The authors notice that great capacity of collaboration between the students must exist to introduce them into the object of course development. Nevertheless the collaboration does not appear as an important part in the structure of design, and the model does not consider the student as a process center.

\section{Learning process in virtual education or "e-learning"}

In the definition of e-leaning shown in section 1 , the student must be included as the center of process learning, and the human collaboration as the fundamental support for the awaited success. "The Virtual University term would have to include a systemic concept" [7], where it is possible to capture knowledge, research, develop projects, supply society solutions, participate in forums, diverse problems, specialized events, scientific events, cultural events, etc. The first problem is human contact necessity; people need to be in contact with other people, to share with them their activities, which means to share their problems, hopes, and solutions.

\section{Adapted model of IEEE platform}

We must assure the quality level of actual education, eliminating the possibilities that students pass through nonexistent instruction in an e-learning program. Risks and desertions always exist. We must promote a new type of student, one making more effort, and who will have to change from a passive receiver to a constructive asset in the learning process. A designer must identify significant profiles of students, such as age, language, knowledge, learning strategy preferred, time available, motivation, experience, etc. Motivation is provided by the professor when he observes deficiencies, negligence or poor points in a student and then explains to the student that he must make an additional effort and how he must do so. Perhaps this does not happen in e-learning the way we know it, but we will have to take care to identify these situations. Adapting the IEEE model about "Learning Technology Support Architecture System Components" (LTSASC) we included two processes: we can call reload capacity in (1) collaborative work process and the formation of student communities; (2) a process of educative networks, where human and social activities are integrated (see Figure 1).

We must count with measured mechanisms and evaluation of results, and then be able to support increasing demand without losing quality [1]. We know that similar learning technologies do not have similar predictable results. Their effects are determined by the decisions that people in charge take from the educative policies, and these decisions are in many cases determined by the paradigm model of a university, that implicitly or explicitly has the political people in charge. 


\section{Proposal of agents}

Figure 1 shows the proposal for the new processes:

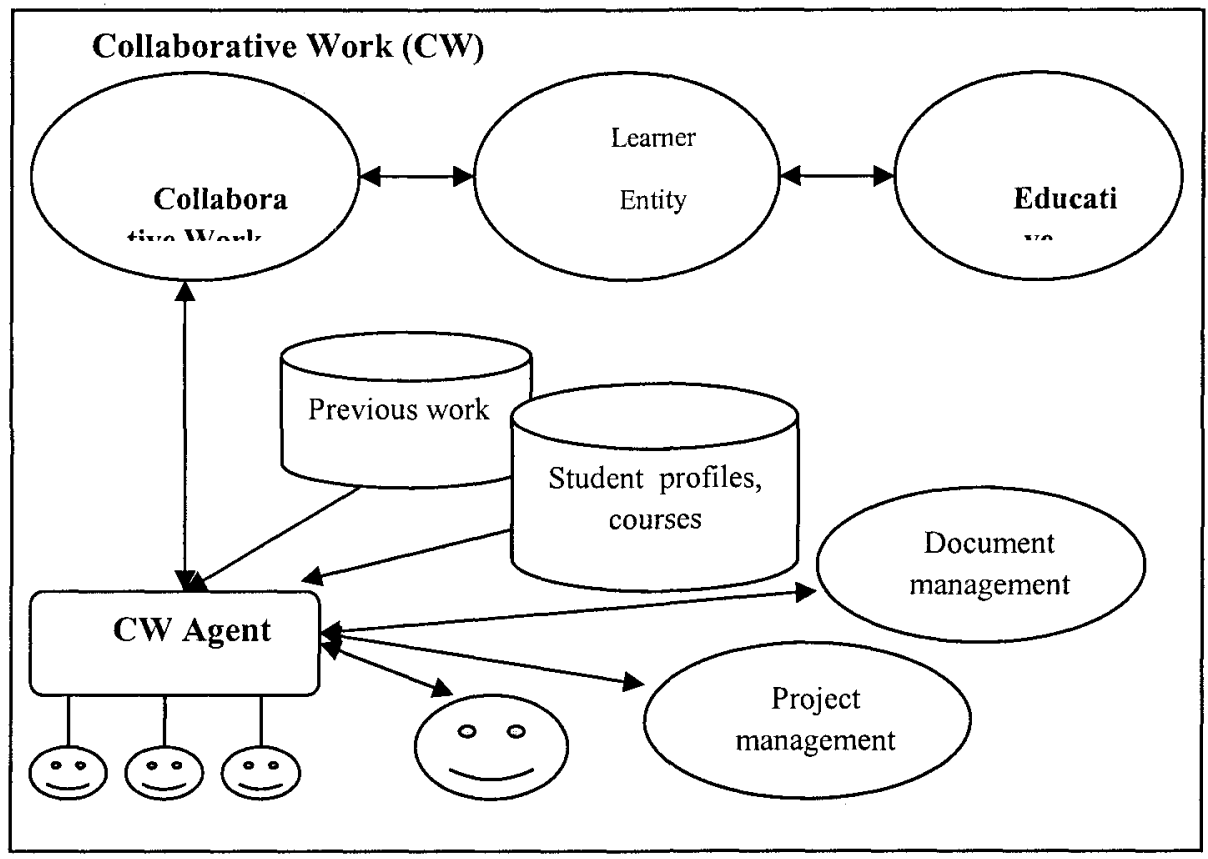

Figure 1. Proposal of agents for collaborative work.

The collaborative work agent model will be designed to capture useful information referred to: (1) formation of groups, with the knowledge of student profiles. They have obtained previous works and valued a balance between the proposed selection. This selection will have to be stored for future projects; (2) the agent will manage digital documents constructed with the support of algorithms that tell if a document has been opened by the student and to which page the student has advanced in their reading, and then how much time he has dedicated to each page. With these elements we will be able to obtain advance indicators and to analyze strategy types to recommend to the students; and (3) project management: it is possible projects repeat themselves, and the agent evaluates the validity of projects with previous considerations proposed by the tutors, as the content, goals and the scene of application that corresponds to the project viability.

A similar model is proposed for the agents for the Network of Educative Collaboration (human and social). The Educative Networks are social networks. The agents have different roles to fulfill related to the human side of students. It is necessary to prepare the design with moral and ethical components, and there is a reason for making a deeper analysis in order to decide if we can allow different types of behaviors of the students so that they trust. At the moment the design will be open to receive communications and to propose interactions with students for friendship subjects, culture, sports, entertainment, and social aid, among others, 
where the values will be to distinguish and to capture them, like affection and satisfaction that they give and receive from their environment.

\section{Conclusions}

Our approach is that the student can learn to identify moral, ethical and human questions that definitively always have been in learning. We looked for the center of the learning process in the students, and human collaboration with its surroundings, to construct learning examples in different disciplines that can be reused and be improved, to promote collaboration among students. The learning atmospheres must adapt their behavior to students, motivating collaborative work and the construction of social activity networks. For each process we must explore social and cultural interchanges, new ways of collaboration, in freedom and with ethical responsibility. The systems also must provide intelligence for facilitating and managing the learning activities of students, the collaboration among students, and the interactions among students, teachers and the learning objects Too much of the work we have to do is related to confronting the social demands about education in the university, and among them we must improve the quality and ethics issues in order to educate students in ways to confront the future successfully in future generations.

\section{References}

1. Arteaga, C.; Fabregat, R. Integración del aprendizaje Individual y del colaborativo e un sistema hipermedia adaptativo. Universitat de Girona (UdG) http://eia.udg.es/ atm/bcds/pdf/carlos_arteaga_jenui02_cameraready.pdf

2. Bernuy, A. Evaluación Calidad de Educación Virtual en Educación Superior. 3er Congreso Internacional TIC y Tecnología Multimedia en Educación, MICTE 2005, FORMATEX, Extremadura

3. Chacòn, Fabio. Mind-Mapping for Web Instruction and Learning; Franciscan University of Steubenville

4. Gagne, R.M. The conditions of Learning and Theory of Instructions, New York CBS College Publishing. http://www.apsique.com/tikiindex.php?page=apregagne

5. Kaplùn M. Revista Chasqui Nro. 58, Junio 1997. http://www.comunica.org/chasqui/kaplun.htm

6. Martín. V. La formación en valores: una aproximación al aprendizaje ético. Sociedad y Utopía. Revista de Ciencias Sociales, $n^{\circ} 25$ Mayo 2005. Madrid

7. Sangrà, A. La Calidad en las experiencias virtuales de educación superior, UOC

8. IEEE LTSA Model in http://grouper.iee.org/LTSC/wg1/files/ltsa-400.pdf 